\title{
Data Analytics Solutions for Transforming Healthcare Information to Quantifiable Knowledge - an Industry Study with Specific Reference to ScienceSoft
}

\author{
Geetha Poornima $K^{1,2}$ \& Krishna Prasad $K^{3}$ \\ ${ }^{1}$ Research Scholar, Srinivas University, Mangaluru, Karnataka, India \\ ${ }^{2}$ Assistant Professor, Dept of Computer Science, St Philomena College Puttur, Karnataka, \\ India \\ ${ }^{3}$ College of Computer Science \& Information Science, Srinivas University, Mangaluru, \\ Karnataka, India \\ Email: poornima.sanjay@spcputtur.org
}

Area of the Paper: Information Technology.

Type of the Paper: Case Study.

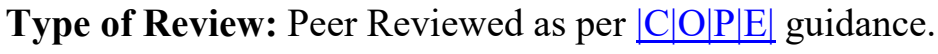

Indexed In: OpenAIRE.

DOI: http://doi.org/10.5281/zenodo.3766907.

Google Scholar Citation: IJCSBE.

How to Cite this Paper:

Geetha Poornma, K. \& Krishna Prasad, K. (2020). Data Analytics Solutions for Transforming Healthcare Information to Quantifiable Knowledge - an Industry Study with Specific Reference to ScienceSoft. International Journal of Case Studies in Business, IT, and Education (IJCSBE), 4(1), 51-63. DOI: http://doi.org/10.5281/zenodo.3766907.

International Journal of Case Studies in Business, IT and Education (IJCSBE)

A Refereed International Journal of Srinivas University, India.

(C) With Authors.

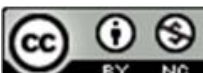

This work is licensed under a Creative Commons Attribution Non-Commercial 4.0 International License subject to proper citation to the publication source of the work.

Disclaimer: The scholarly papers as reviewed and published by the Srinivas Publications (S.P.), India are the views and opinions of their respective authors and are not the views or opinions of the S.P. The S.P. disclaims of any harm or loss caused due to the published content to any party. 


\title{
Data Analytics Solutions for Transforming Healthcare Information to Quantifiable Knowledge - an Industry Study with Specific Reference to ScienceSoft
}

\author{
Geetha Poornima K ${ }^{1,2}$ \& Krishna Prasad K ${ }^{3}$ \\ ${ }^{1}$ Research Scholar, Srinivas University, Mangaluru, Karnataka, India \\ ${ }^{2}$ Assistant Professor, Dept of Computer Science, St Philomena College Puttur, Karnataka, \\ India \\ ${ }^{3}$ College of Computer Science \& Information Science, Srinivas University, Mangaluru, \\ Karnataka, India \\ Email: poornima.sanjay@spcputtur.org
}

\begin{abstract}
Big Data Analytics (BDA) has brought revolutionary changes in many fields. The areas of application such as banking, education, manufacturing, farming, government, transport, media, and entertainment are the ones that make extensive application of BDA. Healthcare is the one that has experienced drastic changes because of BDA. Due to the positive effects of big data, risky jobs like diagnosis, reporting, CRM, predicting the deceases, tracking medical records has become much easier these days. ScienceSoft is an IT company providing information technology services in emerging areas such as CRM, Data Analytics, Collaboration, Knowledge Management, Information Security, etc. ScienceSoft's headquarters is located in McKinney, USA. Organizations such as IBM, Microsoft, Oracle, etc. are collaborating with ScienceSoft due to the reliable and high-quality services provided. This paper attempts to give a broader outlook of Big Data, analyzes the company's business models for handling Big Data Analytics related projects, particularly in the healthcare sector. This paper also contains information related to the challenges of analyzing Big Data, the Company's technologies and tools that are needed in the development of BDA projects and how Big Data is converted into useful knowledge to deliver better results in healthcare allied sectors.
\end{abstract}

Keywords: ScienceSoft, Big Data, Data Analytics, CRM, Healthcare Data, EHR, Data Analyzing Tools.

\section{INTRODUCTION :}

The healthcare sector produces vast quantities of data. Hospitals in most cases do not preserve the data in a standardized format. Healthcare (HC) documents had been in the form of paper documents a decade earlier. Owing to the increasing transition towards digitalization, there is an immediate need to manage large data upstream securely and effectively. There is a heterogeneous dimension of health care information. As it includes static information such as clinical reports, electronic medical records (EMRs), MRI scans, X-ray images, and even quantitative data such as blood pressure, temperature, etc. All these cannot be stored using DBMS. Big Data Analytics (BDA) is deployed to deal effectively with the situation. Effective identification and analysis of any disease involve the processing of vast quantities of historical data. It includes the length of hospitalization, surgery details if any, hazards for medical complications, specifics of hospital-acquired disasters if any, etc. The key concept behind using BDA in the $\mathrm{HC}$ sector is to provide patients with better treatment without additional financial overhead for the individuals [1].

ScienceSoft, a US-based IT company established in the year 1989. It is providing solutions in the field of IT, Telecommunication, Transportation, Data Governance, Machine Learning, IoT, Cyber Security services and many more. In BDA it has been providing customized solutions from the past 14 years. 
BDA will be combined with promising areas such as the IoT, Artificial Intelligence, Machine Learning, Augmented Reality and Computer Vision to meet the needs of hundreds of customers. This case study uses BDA to disclose the company's services in the healthcare sector. [2-4]. This paper includes the objective of the study, an overview of the concept, its applications, role of ScienceSoft as a BDAService Provider, companies contribution in Healthcare, techniques used to analyze Big Data, challenges in BDA and tools used in BDA.

\section{OBJECTIVES OF THE STUDY :}

This industry study is designed to identify the products produced by ScienceSoft for turning Big Data into useful knowledge. This research is conducted using the information gathered from the company's website and related information from other online documents [2-6]. The objectives are :

- To know different BDA applications

- To understand more about BDA in Healthcare

- To study the services provided by ScienceSoft in healthcare

- To learn about the tools used in BDA

- To suggest and recommend new solutions to the company

\section{RELATED WORK :}

Over the years, ScienceSoft has contributed significantly to the field of BDA providing customized solutions to the customers around the globe. But very limited work has been done in analyzing the business model and strategies of the company we considered (table 1).

Table1: Related work in the field of the case study of IT companies and BDA in HC.

\begin{tabular}{|c|c|c|c|c|}
\hline SN & Author & Reference & Topic & \begin{tabular}{|c|} 
Field \\
\end{tabular} \\
\hline 1 & Dennis et al. [7] & 1993 & Business process reengineering & $\begin{array}{l}\text { Case study of IT } \\
\text { company IBM }\end{array}$ \\
\hline 2 & Davenport et al. [8] & 2012 & Big data and it's future in $\mathrm{HC}$ & How BDA is different \\
\hline 3 & Guptha \& Charu [9] & 2013 & $\begin{array}{l}\text { Work-Life Balance in case of } \\
\text { Employees }\end{array}$ & $\begin{array}{l}\text { Case study of } \text { IT } \\
\text { company IBM and } \\
\text { Wipro }\end{array}$ \\
\hline 4 & Jagadish et al.[10] & 2014 & Issues and Challenges in BDA & BDA in $\mathrm{HC}$ \\
\hline 5 & Bates et al.[11] & 2014 & $\begin{array}{l}\text { Using BDA to analyze high-risk } \\
\text { patients }\end{array}$ & Predictive analytics \\
\hline 6 & Archenaa, \& Anita [12] & 2015 & $\begin{array}{l}\text { A survey of big data analytics in } \\
\text { healthcare and government. }\end{array}$ & Application of BDA \\
\hline 7 & Reddy \& Kumar [13] & 2016 & $\begin{array}{l}\text { Predictive big data analytics in } \\
\text { healthcare. }\end{array}$ & BDA Tools \\
\hline 8 & Wu et al.[14] & 2016 & Big data a future of $\mathrm{HC}$ services & BDA techniques \\
\hline 9 & $\begin{array}{l}\text { Qudrat-Ullah \& } \quad \text { Tsasis } \\
\text { [15] }\end{array}$ & 2017 & $\begin{array}{l}\text { Innovative Healthcare Systems for the } \\
21 \text { st Century }\end{array}$ & Innovations in $\mathrm{HC}$ \\
\hline 10 & Johiri et al. [16] & 2018 & $\begin{array}{l}\text { Vitality of big data analytics in } \\
\text { healthcare department. }\end{array}$ & $\begin{array}{l}\text { Importance of BDA in } \\
\mathrm{HC}\end{array}$ \\
\hline 11 & Wan & 2018 & Benefits and challenges of Big Data & BDA and $\mathrm{HC}$ \\
\hline 12 & $\begin{array}{l}\text { Ambigavathi \& Sridharan } \\
{[18]}\end{array}$ & 2018 & Big Data in $\mathrm{HC}$ & Future of BDA \\
\hline 13 & Shahbaz et al. [19] & 2019 & $\begin{array}{l}\text { Investigating the adoption of big data } \\
\text { analytics in healthcare }\end{array}$ & $\begin{array}{l}\text { Implication of BDA in } \\
\mathrm{HC}\end{array}$ \\
\hline 14 & Galetsi et al. [20] & 2020 & $\begin{array}{l}\text { Big data analytics in health sector: } \\
\text { Theoretical framework, techniques and } \\
\text { prospects. }\end{array}$ & BDA techniques \\
\hline
\end{tabular}

\section{GENERAL IDEA OF BIG DATA ANALYTICS :}

BDA is a complex method of exploring big datasets to reveal hidden patterns or unknown relationships, the analysis of which will enable an organization in the process of decision-making. In several fields 
of information technology, it has brought revolutionary changes. Big Data contains datasets that are of type audio, video, text, customer transactions, activity logs of users on the social networking sites, etc. The collected data must be analyzed using algorithms and converted to the required information that can be used for further analysis to reach a conclusion or make a decision. The real challenge is to take out meaningful information from a large pool of data [21-22].

\section{Characteristic Features of Big Data :}

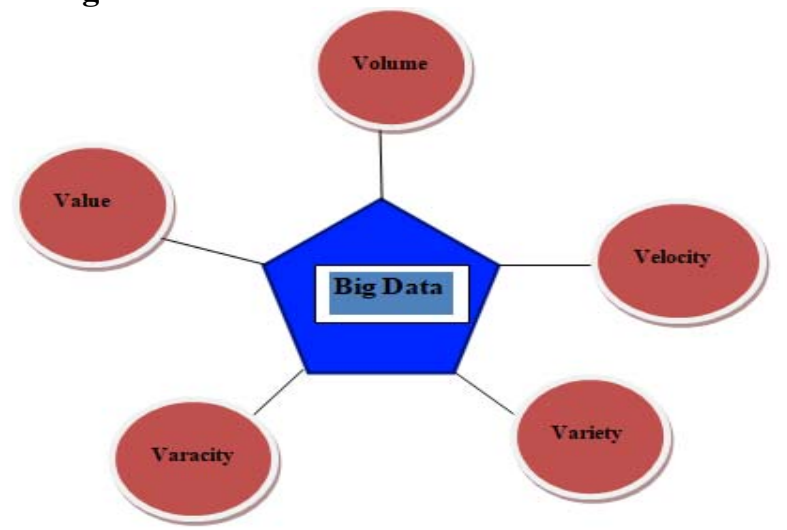

Fig.1: Properties of Big Data

- Volume: Big Data's main feature is the vast amount of data obtained from different sources. The collected data will be in or even more of Tera Bytes. Companies such as Amazon and Facebook generate huge amounts of data. Every customer log creates data and every activity by the user on the social networking site creates data that needs to be captured for analysis [21].

- Velocity: In this era of automation, it is not always necessary to feed the required data manually. Data loads are created automatically or at a faster rate with less human interference. Moreover, this data blizzard needs to be quickly stored and processed. Velocity refers to the speed at which any system that applies Big Data Analysis collects, stores and processes the data [10-11].

- Variety: By fact, the information collected from different sources will always be unstructured. There will be a wide variety of data collected from various resources. The data will also be in various forms, such as a file or a map or a text message [21].

- Veracity: There is no guarantee that all the data collected will be sufficiently good for processing. Fair, bad, and dirty information will be available. The quality of the data collected depends on the validity or authenticity of the sources [21].

- Value: To store and process the massive amount of od information being collected; major investment is needed. There must be some way of turning data volumes into useful information that will add some value to the decision-making process [21][22].

\section{SIGNIFICANCE OF BDA IN HEALTHCARE :}

- BDA eliminates data processing overheads such that healthcare professionals spend more time taking care of their patients than reading the patient records.

- With the help of BDA, it is easy to figure out the hidden relation or association with whether either of two or more events or attributes

- With the help of BDA, it is possible to provide customized HC service thereby increasing customer satisfaction and enhancing service quality

- Clinical decision-making with the help of BDA is made simple [23].

\section{APPLICATION AREAS OF BIG DATA ANALYTICS :}

BDA is used in multiple fields. Many areas use Big Data Analytics extensively. Some of them are listed below:

- Customer Tracking: Through the Internet, consumer transaction generates information that will be useful in assessing the needs, tastes and desires of the customer. The data collected in this way will be used to design products based on customer needs [24][25]. 
- Predictive Analytics: Complex statistical algorithms and techniques of machine learning are used based on historical data to predict future events. This evaluation will help organizations in the decision-making process [25].

- Fraud Detection: There is a lot of possibility of fraud in the banking sector. By reviewing transaction logs, transactions are made by stakeholders. Such details have become a big scam in making online transactions. Big data analysis can be used for identifying fraud to evaluate anomalies in transactions and to find differences in transactions there [26].

- Healthcare: This is the field where Big Data Analysis is used well. By tracking information such as heartbeats, blood pressure, patient sleep patterns, and breathing, the device may predict infections before the person has any symptoms of the same [27].

- Health History Analytics: This includes researching details of ancestors', lifestyles, dietary preferences, work culture, and case history to determine possible threats from disease development [1].

- Public Health: BDA is extensively used in public health care to analyze the disease patterns and trace the disease outbreaks. This will be useful in preventing the spreading of epidemic diseases [1].

- Sports: Sports is another prominent field in which Big Data Analytics is used. Video analysis can be used to recognize players' strengths and weaknesses in a squad and other team players as well as to build winning strategies. Data from wearable devices can be used to monitor players' health and provide them with a diet [25].

- Education: A huge amount of student-related data will help assess students ' learning disabilities. BDA can also be used to increase learner performance and create tailor-made courses for students [26].

\section{SCIENCESOFT AS A BIG DATA ANALYTICS SERVICE PROVIDER :}

ScienceSoft was founded in 1989 as a software development company. It provides information technology services in various fields such as testing and quality assurance, IT consultancy, data analytics, cyber security, and network services. To build quality solutions, it integrates all emerging technologies with BDA. It has been providing services to businesses such as Amazon, eBay, Nestle, etc. for the last 30 years. Customer retention accounts for more than 70 percent of its annual income. IT giants like Microsoft, IBM, etc. have become business partners because of their deep roots in the field of CRM and Data Analytics. It is listed on the Silicon Review listing as one of the top ten fastestgrowing data analytics company. The organization has been offering BDA products for the past 14 years. The main activities of the organization were handled by its McKinney headquarters. Yet at Vantaa, Finland, it has another office.BDA being its core expertise, the company has built several applications in the field of healthcare, banking, and financial services and manufacturing. More than 30 years of experience in the IT industry, 178 active customers $\$ 60 \mathrm{M}$ of annual revenue are the testimony for the success of the company.

Since 2008 the organization has been Microsoft Sharepoint's strategic partner supporting Microsoft's goods and technologies worldwide. The jointly delivered initiatives include HC, retail, Oil \& Gas, Telecom, Banking, etc. The company has been working in the area of security intelligence like IBM's business partner for 16 years. The services provided include quality control and software testing, IT consulting, managed IT services, network services and IT solutions using BDA, IoT, etc. The firm has been Oracle's strategic partner in predictive analytics and visualization of OLAP. Some of the firm's notable collaborations include PimCore, ServiceNow, Microsoft Dynamics 365, Magneto, Ispirer [6],[20].

The company has several long-term clients which include a company that has operational units spread across more than 110 countries. It also developed customized healthcare solutions for more than 200 hospitals and retirement homes of the USA. [6],[26].

\section{HEALTHCARE SERVICES PROVIDED BY SCIENCESOFT :}

Institutions that provide services in the field of healthcare use big data in every available form to improve the quality of their services. They aim at providing the best possible solutions without increasing the cost. When dealing with healthcare data analytics, data is captured from various sources 
such as patients, physicians, lab reports such as PET scan, MRI scan, CT scan, Blood Reports, Ultra Sound Scans, etc. The data so gathered will be unstructured. It has to be stored and analyzed for effective decision making. It must be stored and analyzed for effective decision-making reasons. The company provides services to more than 200 United States healthcare institutions. It has designed solutions available to fulfill the needs of the institutions [26]. Services offered by the company in the field of healthcare include the following:

\subsection{Intelligent Healthcare System}

Intelligent Healthcare System accepts the data from the patient with the help of a Mobile App. Since the symptoms of every decease are different, every decease requires different mobile apps. The mobile apps handle all communications between the patient and the software. Entire data related to a patient will now be recorded in each patient's Electronic Health Recorder (EHR), which includes pati ents' health information in electronic format. Intelligent Healthcare System accepts the data from patients and stores them in EHR. Data thus stored is used by the Data Analytics Software to provide a clear analysis of the patient's present health conditions. The reported related to the analysis will be given to the doctor in the form of notification and the doctor after going through the analyzed data will notify the patient regarding the treatment with the help of a mobile app [28].

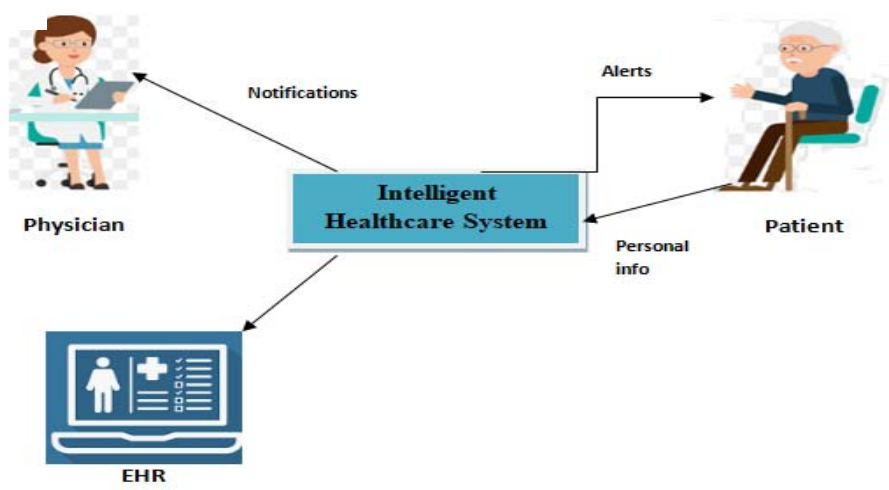

Fig.2: The functioning of the Intelligent Healthcare System

Figure 2 demonstrates the operation of the Smart System of healthcare. It is used by patients with chronic diseases such as diabetes, asthma, heart problems, behavioral problems, knee joint pain, etc. Patients enter their illness details, food information, disorders such as muscle pain, blood pressure, blood sugar levels and allergies to drugs, if any, with the help of a mobile app. The Intelligent Healthcare System will send all data to the EHR. A centralized data warehouse will be in operation where all the data will be stored. The algorithms for data analytics use the information stored in the EHR to determine the patient's present situation. This analyzed information is given to the doctor in the form of notifications that further analyze the patient's information and send the patient personalized information. Using the mobile app, the patient must read the doctor's recommendations. The customized knowledge will include medication to be taken, the food to be eaten and avoided, the physical activities to be carried out and to be avoided, the schedule of appointments and the details of lab reports. This ensures two-way communication between caregivers and patients.

\section{Benefits}

- It saves a lot of time.

- Up to date information about the patient will be available

- There will be continuous monitoring of patients

- Scheduling of appointments is easy as the doctor knows the current situation of the patient

- Quality of service provided to the patients is improved

- The patient can access his data any time

- Customer (patient) satisfaction is improved

Drawbacks

- There will be security and privacy issues related to the patient's data. To overcome these issues, the records are stored and handled by an authorized third party. 
- Accessing the information related to a patient by himself will create unnecessary tension.

- Records must be updated after receiving input from patients and after their every visit to the hospital and laboratories otherwise it will lead to inaccurate results [29].

\subsection{Image Investigation in Medical Sciences}

Analysis of the image is very much necessary in medical science. The study of images is a multidisciplinary field involving complex algorithms, physics, mathematics and many more. It includes X-Rays analysis, the examination of CT Scan reports, MRI Scan reports, PET scan reports, Ultra-Sound Scanning reports, etc. have become an essential part of medical diagnosis. It also provides customized solutions that involve 3D imaging for the spinal cord, brain, liver, kidney, gall balder, etc to find out the exact location of the infection. The photos will be in a different format created by each medical device. In the data warehouse, the images obtained from different instruments are recorded and data analytics algorithms are developed to obtain accurate results. In short, this is used to detect the exact location of tumors in the brain and cancer cells. Medical image analysis program uses

- Software to improve the captured image quality. If the captured image is not of the required quality, computer algorithms are used to generate a clear image form the existing one.

- Segmentation method for determining the exact area and separation of infected cells from non-infected cells; It should help prevent damage to healthy cells which is very necessary for brain cancer diagnosis.

- Machine learning algorithms are used for the diagnosis so that the decease is diagnosed at an earlier stage. This will enhance the survival rate of the patients.

Medical Image Analysis is used to diagnose accurately abdominal deceases, brain tumors, spinal cord related diseases, diseases related to mammary glands, respiratory organs and kidneys [30].

\subsection{Cancer Drug Manufacturing System}

ScienceSoft is providing smart solutions to a multi-national company that manufactures generic and non-generic cancer drugs that are used in chemotherapy. The shelf-life of these drugs will be very short hence they require smart manufacturing to avoid overstock and out of stock situations. In most of the situations, the medicines used in chemotherapy are combinations of several drugs. The dosage and the combination vary from patient to patient. ScienceSoft implemented the solution by making use of the .NET framework. Hospitals and Drug houses use the software to place their orders. The order information is stored in databases for further analysis. As per the order, the customized drug is manufactured and supplied to the patient. At any time, the patient can track their order.

This system is used to maintain the stock of drugs, the stock of chemical compounds used to manufacture those drugs, update inventories and automate billing and payment processes. In addition to this, the software will generate different types of reports such as hospital reports, patients' reports, drug reports, stock reports, etc. BDA algorithms are used in the manufacturing process to reduce the wastage of medicines because of excess stock [31].

\subsection{In-patient Mobile Care Applications}

ScienceSoft developed a comprehensive mobile-care platform for European client's in-patients. The program provides round the clock support to in-patients. This provides them with the ability to connect with their care providers, health personnel, receive drug alerts, etc. They are allowed to watch TV shows of their choosing, listen to music or watch videos with the aid of tab, to relieve the discomfort, pain, and stress. This will keep them engaged. Besides, the app also gives room temperature adjustment facilities, turning off / on lights and fans request for wheelchair access, ask for personal hygiene assistance, ask for food, water, etc. They also have access to their schedules. This type of apps provides better care for elderly people [26].

\section{5 Other Useful Health Care Applications}

ScienceSoft has created a series of Android Apps for engaging patients, educating patients on health and hygiene, fitness tracking systems, medication remainders, addiction tracking systems, mindfulness and relaxation systems. Smart devices that monitor blood pressure, thermometers, sleep monitors, heart rate monitors, etc. can easily integrate these apps to provide better care for the needy. They inhibit twoway communication between patients and their caregivers. To provide up-to-date patient-related information, all patient mobile apps and smart devices need to be connected to HER [24].

\section{SWOC ANALYSIS :}


A company's success relies on a variety of factors both internal and external to it. SWOC analysis enables the enterprise to gain a clear understanding of its business and to discover new avenues to improve its business. The company's success and tactics are compared with that of rivals in SWOC analysis. The strength identified will generate more and more opportunities and the company should focus more on overcoming its weaknesses [32-35].

\begin{tabular}{|c|c|}
\hline STRENGTHS & WEAKNESSES \\
\hline $\begin{array}{l}\text { - Strong reputation for the company } \\
\text { - Wide variety of cost efficient solutions } \\
\text { - Effective customer retention policies } \\
\text { and employee management strategies } \\
\text { - Efficient Customer Service } \\
\text { - Clear rules of business }\end{array}$ & $\begin{array}{l}\text { - The need to train the user to use the } \\
\text { solution } \\
\text { - difficult to integrate BDA solutions } \\
\text { with available infrastructure and } \\
\text { applications } \\
\text { - Data collection and transition loophole } \\
\text { - Data protection Issues }\end{array}$ \\
\hline CHALLENGES & OPPORTUNITIES \\
\hline $\begin{array}{l}\text { - Data protections issues } \\
\text { - Rigorous tax and outsourcing policies } \\
\text { of the Government } \\
\text { - Intense competition in the global } \\
\text { market } \\
\text { - Challenges related to consumer } \\
\text { expectations and priorities } \\
\text { - Hidden costs in backup, recovery and } \\
\text { service }\end{array}$ & $\begin{array}{l}\text { - Offer business approaches to emerging } \\
\text { ICT trends } \\
\text { - Inculcate new technologies in } \\
\text { designing solutions } \\
\text { - Expand operational areas and fields } \\
\text { - Incorporate more protection and data } \\
\text { integrity to solutions } \\
\text { - Provide an environment conducive to } \\
\text { the work force }\end{array}$ \\
\hline
\end{tabular}

Fig.3: SWOC analysis of the Company

\section{COMPETITORS OF SCIENCESOFT COMPANY}

As a global corporation, it faces intense competitors in the global technology market. due to its clientcentric business model, innovative workforce, enhanced quality of service (QoS) and costeffectiveness, it is considered to be one of the most admired IT companies providing personalized solutions in BDA [36].

Table2: List of Companies providing BDA services in HC

\begin{tabular}{|c|l|c|c|c|}
\hline SI No & \multicolumn{1}{|c|}{ Name of the Company } & No. of Employees & $\begin{array}{c}\text { Year of } \\
\text { Establishment }\end{array}$ & $\begin{array}{c}\text { Annual Income } \\
\text { in Million \$ }\end{array}$ \\
\hline 1 & ScienceSoft & 700 & 1989 & 60 \\
\hline 2 & Cloud Task & 205 & 2012 & 53.5 \\
\hline 3 & Coastal Cloud & 250 & 2012 & 32.3 \\
\hline 4 & Switchfast Technologies & 100 & 2001 & 65.7 \\
\hline 5 & Skaled & 35 & 2013 & 38.2 \\
\hline 6 & McAfee Security Services & 7600 & 1987 & 7400 \\
\hline 7 & LeadMD & 38 & 2009 & 40.7 \\
\hline 8 & ATG Consulting & 50 & 2007 & 15 \\
\hline 9 & SmartSites & 90 & 2011 & 10 \\
\hline 10 & Code Zero & 60 & 2016 & 7.4 \\
\hline
\end{tabular}

\section{TECHNIQUES USED TO ANALYZE BIG DATA :}

BDA requires sophisticated techniques to analyze huge amounts of data. Several techniques can be used to make simple knowledge from voluminous data. They are to be selected depending on the type of application [24]. Some of them include:

- Association rule mining: This approach is used in the case of large datasets to find the hidden relationship between two or more variables. It is commonly used in supermarkets to know the relationships between buying different items. 
- Classification tree analysis: This technique is used for categorizing the data. It requires prior information and knowledge of the problem. It is used to automatically categorize the documents. It is commonly used in the disciplines of healthcare

- Genetic algorithms: Using this approach, the features of two or more things are combined to form a new one with better features. It is widely used to build new products from existing ones. It includes two operations- mutation and crossover.

- Machine learning: This is an Artificial Intelligence technique that requires a large number of training sets. Without the aid of explicit software, computers learn automatically in machine learning. It is commonly used to assess the disorder in health.

- Regression analysis: In this technique, some independent variables are manipulated to see the influence on some other variables. It is the most efficient technique to deal with quantitative data. It is used in business, real estate, weather forecasting, etc.

- Sentiment analysis: It involves the analysis of feelings of patients, feelings of customers and opinions of the public. It is used widely in healthcare and hospitality sciences. This method is also used in analyzing the behavior and feedback of customers for making improvements in the hotel and hospitality industries.

- Social network analysis: It is the analysis of interpersonal relationships for commercial reasons. This is a popular technique applied in the analysis of security applications, internet applications, etc to find out the correlation between two or more variables.

\section{BENEFITS OF BDA IN HEALTHCARE :}

- Up to date information can be given to patients thereby making the healthcare process more accessible and user

- Diseases can be predicted before being fully unmanageable for both patients and caregivers

- Doctors can easily access patient real-time data

- False claims on health insurance can be prevented

- The target group for the assessment of a disease or medicine can be easily identified

- BDA integrates patients, caregivers, pharmacists, drug manufacturers, and R\&D personnel so that new or more effective drugs can be delivered easily [31].

\section{CHALLENGES IN BIG DATA ANALYTICS :}

In this digital age, an enormous amount of records are generated every minute. Each online transaction by every individual, every reading on the EHR in case of healthcare creates data of some use. This has to be captured and analyzed for decision making [25],[37]. Few challenges faced in the handling of big data include

- Information from diverse sources: Healthcare data analytics requires data to be collected from various sources such as X-Ray images, ECGs, Ultra-Sound Scanning, medical reports, etc. Since they are from different sources, they will be definitely in a distinct format. Storing data from diverse sources is the biggest challenge. Different formats of data will make it a tough job for selecting proper attributes so that it can be stored properly.

- Shortage of experts: BDA demands voluminous data which is to be accessed and processed periodically. It requires the use of complex algorithms and tools. This field has created ample job opportunities but still, the industry is facing a shortage of experts.

- Selecting appropriate format and data: As data is gathered in different sources, it will there in a different format. Selecting the proper data becomes a challenge as there will be useful data, noise, and inconsistent data. Selecting only meaningful data and processing it is very important in BDA.

- Storage and backup for the data: As the data grows exponentially, selecting the right storage medium is a very important factor because the proper storage medium has a high impact on the time required for the retrieval of required data.

- Security and privacy issues: Voluminous data needs to be protected properly. Safeguarding sensitive information is the most challenging task of BDA. There will be difficulty in the recovery of a massive amount of data is lost due to a lack of proper security measures. 
- Misuse of data is possible: Insurance companies can access the private data related to customers and there is a possibility that they may misuse it.

\section{AVAILABLE BDA SOLUTIONS :}

BDA tools are nothing but software that are used in the analysis of a large amount of data for providing the required knowledge. They are widely used for large amounts of data visualization. There is a range of products in the market [38]. Some of them include:

- Apache Hadoop: It is an open-source framework that is widely used in BDA by the companies that provide services in this field. It is used for research and development considerations.

- CDH (Cloudera Distribution for Hadoop): This is open-source and easy to use the tool. It provides higher security for the data.

- MongoDB: It is a NoSQL document-oriented system. It is an open-source software tool that can be installed on different platforms such as Windows, Linux, Solaris, and FreeBSD. It is easy to learn, cost-effective and reliable. These features made it popular in the field of data analytics.

- R Programming: This tool is used extensively for statistical analysis. It is open-source and dynamic and is broadly used for data visualization. It runs on several platforms.

- Apache SAMOA: This tool is suitable for machine learning. It provides different algorithms that can be used in the case of data mining and machine learning for analysis.

- Lumify: This tool is used for data visualization. It provides 2D and 3D graphs. It is widely used in healthcare data analysis and association rule mining.

- Talend: This is an easy-to-use tool that automates the integration of different types of data. It is used extensively in machine learning and natural language processing.

- Skytree: It is mainly used for artificial intelligence and data science applications. It a software that offers GUI functionality which makes it easy to use.

\section{SUGGESTIONS AND RECOMMENDATIONS FOR THE COMPANY :}

Based on the analysis of the company we suggest that [32-35]

1. The company has to concentrate more on Europian countries and also other parts of the globe to attract potential customers for BDA solutions especially in the field of healthcare and banking

2. To reduce the cost of software, the company should try to make use of automated tools that will reduce efforts required to design different test cases for the effective testing strategy. If automated tools are used, effort, as well as the cost of testing, gets reduced drastically. This, in turn, will reduce the cost of development.

3. Customer needs and tastes go on changing from time to time. The company has to analyze market trends and develop products based on customer needs. This can be effectively done by making use of social monitoring and analyzing tools.

4. To adopt the quickly changing business needs and focus on growth, the company has to provide a flexible organizational structure where the emphasis is given on skills. If the workers are not restricted to a particular department, there will be potential for more innovations

5. The company can widen its market by providing different types of services making use of emerging technologies such as machine learning and artificial intelligence

6. There are many tools available online for evaluating the approaches of competitors and for choosing an ideal business plan that is suitable for business improvement. For the improvement of business, the competitor's strategies are to be analyzed.

\section{CONCLUSION :}

BDA can improve the way healthcare professionals use advanced resources to gain insight into their medical and other sources of knowledge and to make intelligent decisions. In the future, we can see the rapid, widespread implementation and use of BDA in the healthcare sector and the healthcare industry. When BDA becomes more common, issues such as maintaining confidentiality, safeguarding security, setting standards and governance, and constantly developing tools and technology may attract attention. BDA and healthcare technologies are at an evolving stage of growth, but rapid technology 
and technological development will accelerate their maturing process. In this sense, due to the twoway interaction between patients and their care providers, the approaches suggested by ScienceSoft enhance customer satisfaction. Such software applications, in effect, make life smoother for patients.

\section{REFERENCES :}

[1] Raghupathi, W., \& Raghupathi, V. (2014). Big data analytics in healthcare: promise and potential. Health Information Science and Systems, 2(1), 1-10. DOI: https://doi.org/10.1186/2047-2501-2$\underline{3 .}$

[2] Aithal, P. S., (2016). Study on ABCD Analysis Technique for Business Models, Business strategies, Operating Concepts \& Business Systems, International Journal in Management and Social Science, 4(1), 98-115. DOI : http://doi.org/10.5281/zenodo.161137.

[3] Madhushree., Revathi, R., Anil Kumar, \&Aithal, P. S. (2018). Business Strategy of Top Indian IT Company: MindTree. International Journal of Case Studies in Business, IT and Education (IJCSBE), 2(1), 22-36. DOI: http://dx.doi.org/10.5281/zenodo.1249871.

[4] Johansson, R. (2003). Microsoft Word - keynote_030930. 1(September), 1-14. DOI: https://doi.org/ 10.1016/S0148-2963(00)00195-8.

[5] Big Data Analytics - Data Life Cycle - Tutorials point. Retrieved on 6-10-2019from https://www.tutorialspoint.com/big_data analytics/big_data_analytics lifecycle.htm.

[6] Wikipedia. (2019). Big Data. Wikipedia. Retrieved on 2/10/2019 from https://en.wikipedia.org/ wiki/Big_data.

[7] Dennis, A. R., Daniels, R. M., Hayes, G., \& Nunamaker, J. F. (1993). Automated support for business process re-engineering: A case study at IBM. Proceedings of the Annual Hawaii International Conference on System Sciences, 3, 169-178. DOI: https://doi.org/10.1109/HICSS.1993.284309.

[8] Davenport, T. H., Barth, P., \& Bean, R. (2012). How "big data" is different. MIT Sloan Management Review, 54(1). 21-25.

[9] Gupta, S., \& Charu. (2013). Analyzing Work Life Balance and Burnout as Predictors of Job Satisfaction in IT industry of Gurgaon: A Case Study Of IBM \& WIPRO in 2008-10. Journal of Business Management \& Social Sciences Research, 2(12), 2319-5614.

[10] Jagadish, H.V. Johannes Gehrke, Alexandros Labrinidis, Yannis Papakonstantinou, Jignesh M. Patel, Raghu Ramakrishnan, \& Cyrus Shahabi. (2014). Big Data and its technical challenges. Communications of the ACM, 57(7), 86-94.

[11] Bates, D. W., Saria, S., Ohno-Machado, L., Shah, A., \& Escobar, G. (2014). Big data in health care: Using analytics to identify and manage high-risk and high-cost patients. Health Affairs, 33(7), 1123-1131. DOI: https://doi.org/10.1377/hlthaff.2014.0041.

[12] Archenaa, J., \& Anita, E. A. M. (2015). A survey of big data analytics in healthcare and government. Procedia Computer Science, 50(2), 408-413. DOI: https://doi.org/10.1016/j.procs.2015.04.021.

[13] Reddy, A. R., \& Kumar, P. S. (2016). Predictive big data analytics in healthcare. Proceedings 2016 2nd International Conference on Computational Intelligence and Communication Technology, CICT 2016, 623-626. DOI: https://doi.org/10.1109/CICT.2016.129.

[14] Wu, J., Li, H., Cheng, S., \& Lin, Z. (2016). The promising future of healthcare services: When big data analytics meets wearable technology. Information and Management, 53(8), 1020-1033. DOI: https://doi.org/10.1016/j.im.2016.07.003.

[15] Qudrat-Ullah, H., \& Tsasis, P. (2017). Innovative Healthcare Systems for the 21st Century. Innovative Healthcare Systems for the 21st Century, 125(2) 15-70. DOI: https://doi.org/10.1007/978-3-319-55774-8. 
[16] Johri, P., Singh, T., Das, S., \& Anand, S. (2018). Vitality of big data analytics in healthcare department. 2017 International Conference on Infocom Technologies and Unmanned Systems: Trends and Future Directions, ICTUS 2017, 2018-January, 669-673. DOI: https://doi.org/10.1109/ICTUS.2017.8286092.

[17] Wang, Y., Kung, L. A., \& Byrd, T. A. (2018). Big data analytics: Understanding its capabilities and potential benefits for healthcare organizations. Technological Forecasting and Social Change, 126(2), 3-13. DOI: https://doi.org/10.1016/j.techfore.2015.12.019.

[18] Ambigavathi, M., \&Sridharan, D. (2018). Big Data Analytics in Healthcare. 2018 10th International Conference on Advanced Computing, ICoAC 2018, 2015, 269-276. DOI: https://doi.org/10.1109/ICoAC44903.2018.8939061.

[19] Shahbaz, M., Gao, C., Zhai, L. L., Shahzad, F., \& Hu, Y. (2019). Investigating the adoption of big data analytics in healthcare: the moderating role of resistance to change. Journal of Big Data, 6(1). DOI: https://doi.org/10.1186/s40537-019-0170-y.

[20] Galetsi, P., Katsaliaki, K., \& Kumar, S. (2020). Big data analytics in health sector: Theoretical framework, techniques and prospects. International Journal of Information Management, 50(April 2019), 206-216. DOI: https://doi.org/10.1016/j.ijinfomgt.2019.05.003.

[21] Big Data Analytics - What it is and why it matters. (n.d.). Retrieved from https://www.sas.com/en_us/insights/analytics/big-data-analytics. on 3-10-2019.

[22] Broussard, M. (2016). Big Data in Practice. Digital Journalism, 4(2), 266-279. DOI: https://doi.org/ 10.1080/21670811.2015.1074863.

[23] Lee, C. H., \& Yoon, H. J. (2017). Medical big data: Promise and challenges. Kidney Research and Clinical Practice, 36(1), 3-11. DOI: https://doi.org/10.23876/j.krcp.2017.36.1.3.

[24] Collective, S. (2018). Discover the Power of Big Data And Learning Analytics For Education. SmartData Collective. Retrieved on 08-10-2019 from https://www.smartdatacollective.com/ discover-power-of-big-data-learning-analytics-foreducation/.

[25] Big Data Use Cases, Oracle. Retrieved (n,d) from https://www.oracle. com/big-data/guide/bigdata-use-cases.html on 04-10-2019.

[26] Chronic Disease Management Software - ScienceSoft. Retrieved from https://www. sciensoft. com healthcare/chronic-disease-management on 06-10-2019.

[27] 12 Examples of Big Data In Healthcare That Can Save People. (2019, December 10). Retrieved on 09-10-2019 from https://www.datapine.com/blog/big-data-examples-in-healthcare/.

[28] 12 Advantages and Disadvantages of Electronic Health Records. Retrieved from https://vittana.org/12-advantages-and-disadvantages-of-electronic-health-records on 09-10-2019.

[29] Automation of Cancer Drug \& TPN Order and Manufacturing - Case Study. Retrieved on 06-102019 from https://www.scnsoft.com/case-studies/automation-of-cancer-drug-tpn-order-andmanufacturing? $\mathrm{t}=$ none $\& \mathrm{i}=7517 \& \mathrm{l}=\mathrm{EN}$.

[30] Big Data Techniques That Create Business Value. Firmex Resources. Retrieved on 09-102019 from https://www.firmex.com/thedealroom/7-big-data-techniques-that-create-businessvalue.

[31] Big Data Analytics In Medicine And Healthcare. PubMed Central (PMC). Retrieved from https://www.ncbi.nlm.nih.gov/pmc/articles/PMC6340124/ on 12-10-2019.

[32] Aithal, P. S. and Suresh Kumar, P. M. (2015). Applying SWOC Analysis to an Institution of Higher Education. International Journal of Management, IT and Engineering (IJMIE), 5(7), 231247. DOI :http://doi.org/10.5281/zenodo.163425. 
[33] Revathi R., Madhushree \& Aithal, P. S. (2018). Business Strategy of Top Indian Company: L\&T InfoTech. International Journal of Case Studies in Business, IT and Education, 2(1), 64-89. DOI: http://dx.doi.org/10.5281/zenodo.1302770.

[34] Madhushree, Revathi R., Anil Kumar, \&Aithal, P. S. (2018). Business Strategy of Top Indian IT Company: MindTree. International Journal of Case Studies in Business, IT and Education, 2(1), 23-36. DOI: http://dx.doi.org/10.5281/zenodo.1249871.

[35] Aithal, P. S. (2016). Nanotechnology Innovations \& Business Opportunities : A Review. International Journal of Management, IT and Engineering (IJMIE), 6(1), 182-204.DOI : http://doi.org/10.5281/zenodo.161153.

[36] Top 20 Alternatives \& Competitors to ScienceSoft (n. d.). Retrieved from https://www.g2.com/products/sciencesoft/competitors/alternatives on 10-10-2019.

[37] (n.d.). The Usefulness and Challenges Of Big Data In Healthcare | Insight Medical Publishing. Retrieved on 10-10-2019from https://healthcare-communications.imedpub. com/the-usefulnessand-challenges-of-big-data-in-healthcare.php?aid=22237.

[38] Top 15 Big Data Tools (Big Data Analytics Tools) In 2019. Retrieved from https://www.softwaretestinghelp.com/big-data-tools/ on 11-10-2019. 